\title{
Non-linear influences of the built environment on transportation emissions: Focusing on densities
}

\author{
Jinhyun Hong \\ University of Glasgow \\ Jinhyun.Hong@glasgow.ac.uk
}

\section{Article history:}

Received: February 15, 2015

Received in revised form: April 14, 2015

Accepted: May 26, 2015

Available online: September 3, 2015 vehicle type and age). In addition, the self-selection issue can exist in the land use-transportation emissions analysis because transportation emissions are often estimated based on travel behavior. Using the 2006 Puget Sound Regional Council (PSRC) Household Activity survey, the follow-up stated preference survey, the Motor Vehicle Emission Simulator (MOVES) data, and the GIS network data, this study investigates the non-linear effects of densities on $\mathrm{CO}_{2}$ equivalent $\left(\mathrm{CO}_{2} \mathrm{e}\right)$ emissions with the consideration of self-selection. Specifically, quadratic forms of population and employment densities, different population density group indicators, and attitudinal factors are employed in the regression models. The results indicate that people living in denser neighborhoods tend to generate fewer $\mathrm{CO}_{2} \mathrm{e}$ emissions. However, this effect becomes insignificant as population density reaches a certain level.

Keywords: transportation emissions, densities, non-linearity, selfselection

\section{$1 \quad$ Introduction}

Transportation is the second largest greenhouse gas (GHG) emissions source in the United States, accounting for about 30 percent of total GHGs. Advances in vehicle technology such as improved fuel efficiency have reduced transportation emissions per mile significantly but the increased vehicle miles traveled (VMT) and the change in people's preference toward light-duty trucks have weakened the benefits of the technology improvements (EPA 2006). This suggests that reducing auto dependency is one of the main solutions for preserving our communities, and many planners have focused on landuse policies because they believe people's travel behavior can be modified by changing spatial settings.

Copyright 2015 Jinhyun Hong

http://dx.doi.org/10.5198/jtlu.2017.815

ISSN: 1938-7849 | Licensed under the Creative Commons Attribution - Noncommercial License 3.0

The Journal of Transport and Land Use is the official journal of the World Society for Transport and Land Use (WSTLUR) and is published and sponsored by the University of Minnesota Center for Transportation Studies. 
For example, several empirical and review studies showed very significant associations between land-use factors, including densities and accessibility, and diverse types of travel behavior, such as VMT, trip generation, and mode choices (Handy 2005; Ewing and Cervero 2010; Cervero and Duncan 2002; Crane 2000). In general, they found that creating compact neighborhoods with good accessibility reduces auto dependency, resulting in less driving. VMT is highly correlated with the fuel consumption and transportation emissions, thus the above finding supports the potential use of land-use policies to reduce transportation emissions. Moreover, some studies examined the direct relationship between land-use factors and transportation emissions while controlling for other influential factors such as socio-demographics and vehicle characteristics, and found their significant associations (Frank, Stone, and Bachman 2000; Barla et al. 2010; Hong and Goodchild 2014; Lee and Lee 2014).

Even though previous findings provide useful implications to planners and policy makers, most of results are limited because they do not consider a potential non-linear relationship between the built environment and transportation emissions. Transportation emissions are often estimated based on VMT and emissions rate ( $\mathrm{g} / \mathrm{mile})$, and it is possible that there is a non-linear relationship between the built environment and VMT because the reduced travel cost (e.g., time and distance) attributed to the compact development may result in more vehicle trips. In addition, the emissions rate can be higher when driving near the city center rather than suburban areas because of the low travel speed caused by congestion. Finally, there is a significant association between the built environment and vehicle characteristics (Fang 2008) that are highly correlated with transportation emissions. These imply that high density can be associated with fewer transportation emissions due to the reduced VMT; however, its connection could be non-linear.

In addition, several empirical studies showed that self-selection plays an important role in the land use-travel behavior analysis. People who have negative attitudes toward driving may choose to live in compact areas where they can find several alternative transportation modes easily. If so, ignoring the connection between the residential location choice and travel behavior, or traveler's attitudinal factors can result in under- or overestimated effects of the built environment on travel behavior. As mentioned, VMT is the key determinant of transportation emissions, thus the same self-selection issue can exist in the land use-transportation emissions analysis. However, only few land use-transportation emissions studies have taken self-selection into account in their analyses. Therefore, this paper aims to examine the non-linear relationship between densities and transportation emissions while controlling for the self-selection impact by employing quadratic forms of densities and population density group indicators with diverse socio-demographics and attitudinal information of travelers in regression models.

\section{$2 \quad$ Literature review}

\subsection{Land use and travel behavior}

Many empirical studies have been conducted to investigate the relationship between the built environment and travel behavior (Brownstone and Golob 2009; Cao, Xu, and Fan 2010; Cervero 1996; Boarnet and Crane 2001; Chen, Gong, and Paaswell 2008). Several studies produced mixed results, but in general residents in compact and well-mixed neighborhoods tend to drive less and use more nonmotorized transportation modes, resulting in fewer transportation emissions. For example, Ewing and Cervero (2010) conducted a thorough review of previous studies and a meta-analysis to generalize the effects of built environment characteristics on travel behavior. They argued that the weighted elasticity of each land-use factor is not big but the combined effects of several built environment factors such as density, mixed use, and accessibility on travel behavior could be quite large. Zhang et al. (2012) utilized multilevel linear regressions to analyze the effects of diverse built environment factors on VMT, and 
compared four different metropolitan areas, including Seattle, Richmond-Petersburg-Norfolk, Baltimore, and Washington, DC. They found that most built environment factors show very significant impacts on VMT for all case areas, supporting the claim of smart growth strategy. However, their results also produced different effects of the built environment across the case areas, implying the existence of uncontrolled influential factors such as urban area size and transit service coverage.

Due to the complicated relationship between land use and travel behavior, a large amount of research has focused on the methodological issues such as self-selection, trip-interdependency, geographic scales, and so on. For example, some used tour as an analytical unit instead of trip itself (Krizek 2003a; Frank et al. 2008) to consider trip-interdependency, and some measured land-use factors at different geographic resolutions to assess how the effects of the built environment change according to scales (Kwan and Weber 2008; Hong, Shen, and Zhang 2014). In addition, the indirect impacts of built environment factors on auto use through the auto-ownership have been investigated. For example, Zegras (2010) examined both the direct and indirect influences of the built environment on vehicle kilometers traveled (VKT) by modeling vehicle ownership and use together. He found that several meso- and micro-level built environment factors including distance to central business district (CBD), housing type, dwelling unit density, diversity, and local street network have significant influences on auto ownerships and use. However, the results also indicated that some built-environment factors such as dwelling density and diversity only affect VKT indirectly through the auto ownership.

Among these methodological issues, self-selection has been analyzed most intensively (Cervero and Duncan 2002; Krizek 2003b; Handy, Cao, and Mokhtarian 2005; Cao, Handy, and Mokhtarian 2006; Handy 2006; Frank et al. 2007) with several methodological approaches because it could result in the misestimated effects of land-use factors on travel behavior. Mokhtarian and Cao (2008) reviewed and evaluated the pros and cons of seven analytical methods that have been widely used to resolve the self-selection problem. The study concluded that using longitudinal structural equations modeling with the control group is ideal compared to other alternatives to reveal the causal impacts of the built environment rather than association. Brownstone and Golob (2009) employed a joint model of residential density, VMT, and fuel consumption. Interestingly, the results showed that considering a diverse set of socio-demographic characteristics could relieve the self-selection impact. $\mathrm{Cao}, \mathrm{Xu}$, and Fan (2010) attempted to quantify the effects of self-selection by employing a propensity score matching approach. The study found that as people live farther from the city center, they tend to drive more, and the residential location plays a more important role than self-selection in explaining VMT. Several studies measured attitudinal factors to control for self-selection. For example, Schwanen and Mokhtarian (2005) examined the effects of residential neighborhood type dissonance on commute mode choice and employed several attitudinal factors such as travel dislike, pro-environmental policy, pro-high density, and travel freedom in the models. The results showed that travel freedom and pro-environmental factors have significant impacts on the chance of commuting by cars. Cao, Mokhtarian, and Handy (2009) also employed 32 attitudinal questions and identified six factors: pro-bike/walk, pro-transit, pro-travel, travel minimizing, safety of car, and car dependent. They found that travel attitudes and residential preferences have significant impacts on travel behavior; however, the neighborhood characteristics still play an important role in explaining travel behavior while controlling for self-selection. In sum, most studies that considered the self-selection impact still find the significant influences of land-use factors on travel behavior but the magnitudes of estimates are different.

\subsection{Land use and transportation emissions}

Recently, a few studies have estimated the direct impacts of land-use factors on transportation emissions (Frank et al. 2006; Barla et al. 2010) because transportation emissions are not exactly the same 
as VMT. They focused on how to measure emissions from vehicle usage with diverse data sources, and employed statistical models to evaluate their relationship. For example, Frank et al. (2011) examined the impacts of pedestrian infrastructure and urban form on VMT and $\mathrm{CO}_{2}$ emissions per household in King County, WA. The study used link-based $\mathrm{CO}_{2}$ emissions calculated by using the regional travel survey and emissions factors provided by California Air Resources Board. The study's model showed that more pedestrian-friendly urban form is associated with fewer $\mathrm{CO}_{2}$ emissions. Frank, Stone, and Bachman (2000) calculated nitrogen oxides (NOx), volatile organic compounds (VOC), and carbon monoxide (CO) by considering network distance, average trip speed, and engine operating modes with emissions factors from MOBILE5a. Hong and Shen (2014) calculated road-based $\mathrm{CO}_{2}$ equivalent $\left(\mathrm{CO}_{2} \mathrm{e}\right)$ emissions per household based on travel activities, vehicle characteristics, and emissions factors estimated from Motor Vehicle Emission Simulator (MOVES). The results showed that residential density has a very significant negative impact on transportation emissions, and its elasticity changes from -0.16 percent to -0.37 percent depending on the model assumptions.

Some transportation emissions studies employed directly measured data. For example, Friedman et al. (2001) analyzed the effects of several transportation policies for the 1996 Summer Olympic Games on air quality and childhood asthma. The primary pollutants and ozone data were directly collected from the air quality monitoring sites in Atlanta, and results showed significant reductions in ozone pollution and childhood asthma events during the Olympic Games due to the reduced traffic density. In addition, Stone (2007) analyzed the effects of the built environment and sprawl index on aggregated emissions data (i.e., ozone precursor emissions and ozone exceedances per region) and found that some urban form variables have significant associations with emissions.

In summary, most empirical studies show very significant effects of built environment characteristics on transportation emissions while controlling for other relevant factors. However, few studies, to the best of my knowledge, have investigated the non-linear relationship between the built environment and transportation emissions. Frank and Engelke (2005) pointed out that even though transportation emissions are found to be reduced with compact developments, $\mathrm{CO}$ and VOC can highly concentrate in compact neighborhoods due to congestion. Therefore, it is important to examine the potential nonlinear relationship between land use and transportation emissions to better understand their associations and maximize the positive influences of land-use policies. In addition, the self-selection impact should be considered in the land use-transportation emissions analysis due to the direct connection between the estimated transportation emissions and travel behavior.

\section{Data and method}

\subsection{Transportation emissions ( $\mathrm{CO}_{2}$ e emissions)}

Road-based $\mathrm{CO}_{2}$ e emissions per person for two days were estimated based on motorized travel distance per person (miles) and $\mathrm{CO}_{2} \mathrm{e}$ emission factors $(\mathrm{kg} / \mathrm{mile}$ ) with the consideration of vehicle characteristics, number of passengers, road segment speed, and road characteristics. Several datasets including 2006 Puget Sound Regional Council (PSRC) Household Activity survey, MOVES data for Pierce County, WA, and GIS network data were used to estimate $\mathrm{CO}_{2}$ e emissions.

Specifically, $\mathrm{CO}_{2}$ e emissions were calculated in five steps. First, all motorized trips in the survey were regrouped according to the time of trips (i.e., a.m. peak, midday, p.m. peak, evening, and night) to consider the congestion impact. Second, the quickest paths for all motorized trips were found by using the network analysis in ArcGIS. For this step, five GIS network data, according to different time periods with road speeds estimated from the regional transportation model under the congested condition were used. Third, the route information of each trip was linked to road speed (i.e., 16 categories), vehicle

\footnotetext{
${ }^{1}$ The data collected by Pierce County is the most complete local data compared to other counties in the Puget Sound Region. ${ }^{2} 11.29$ and 12.59 passengers for off-peak and peak periods were assumed for bus users based on King County Metro data.
} 
type (i.e., motorcycle, passenger car, truck, and school/transit bus), vehicle age, number of passengers ${ }^{2}$, and road type (i.e., local road and highway). Fourth, this data was merged with $\mathrm{CO}_{2}$ e emission factors estimated by MOVES according to the above speed, vehicle, and road characteristics. Lastly, the road distance per passenger was multiplied by $\mathrm{CO}_{2}$ e emission factors, and the values were summed for each trip and person.

\subsection{Population and employment densities}

PSRC has updated annual population and employment in the Puget Sound region (i.e., King, Pierce, Snohomish, and Kitsap counties) mainly based on the decennial Census and Quarterly Census of Employment and Wages (QCEW), respectively. This region is surrounded by several mountains and large lakes, and many large companies such as Microsoft and Amazon are located in the area.

The 2006 population estimation began with housing unit counts from the 2000 Census. To update housing unit counts, residential building permit data was utilized. Then, local occupancy rates were applied to calculate the number of households. Finally, average household size was multiplied and group quarter population was added to estimate total population. For the employment estimates, data from the State Employment Security Department and supplementary data from other industries such as Boeing were collected and utilized to calculate the total number of jobs in the Puget Sound region. Both estimates were aggregated at the census tract level and are available at the PSRC website. To measure population and employment densities, estimates were divided by the total land area (acres) of each census tract.

Two approaches were employed to examine the relationship between densities and transportation emissions. First, quadratic forms of population and employment densities were included in the analysis to investigate the non-linear associations between densities and transportation emissions. Second, five sub-groups were created based on the number of travelers and population density (i.e., 20 percent of travelers according to density level $)^{3}$, and used as independent variables to test whether the influence of population density has a certain threshold or not. Figure 1 shows the five sub-groups.

Figure 1: Five sub-groups based on the number of travelers and population density

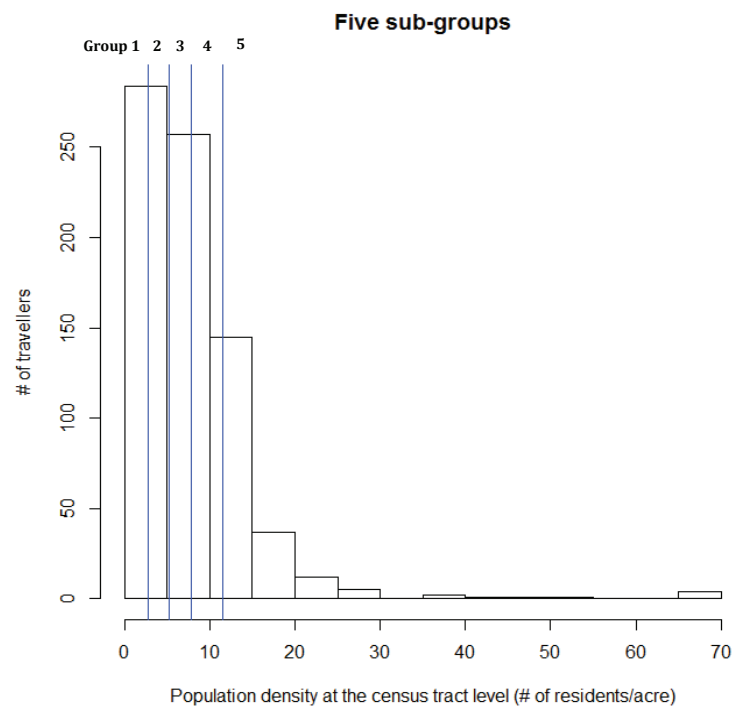

\footnotetext{
${ }^{3}$ Each group has about 150 observations. Different numbers of sub-groups (i.e., six and seven sub-groups) were employed to see how the results changed. The estimates have some variations, but they have a similar trend overall.
} 


\subsection{Attitudinal factors}

One of the widely used approaches for the self-selection problem is to measure attitudinal factors and include them in the travel behavior model (Mokhtarian and Cao 2008). PSRC conducted a follow-up stated preference survey with the adult subset (+16 years of age) of the 2006 PSRC Household Activity survey who fit for the extra experiment for public transit and highway tolls alternatives based on their revealed trips ${ }^{4}$. This survey includes diverse attitudinal questions as well as stated-preference exercises, and 916 adults completed it.

Table 1: Factor analysis for attitudinal questions

\begin{tabular}{lc}
\hline Factors & Loading* \\
\hline Pro-environment & 0.605 \\
\hline I would switch to a different form of transportation if it would help the environment. & 0.827 \\
I would be willing to pay more when I travel if it would help the environment. & 0.436 \\
Use of transit can help improve the environment. & 0.367 \\
\hline People who drive alone should pay more to help improve the traffic congestion situation. & \\
\hline Flexibility & 0.993 \\
\hline I need to have the flexibility to make many trips during the day if necessary. & 0.497 \\
\hline I need to make trips to a wide variety of locations each week. & 0.780 \\
\hline Pro-active transport & 0.371 \\
\hline I am comfortable riding a bus. & 0.352 \\
\hline I would not mind walking a few minutes to get to my destination. & 0.638 \\
\hline Use of transit can help improve the environment. & 0.431 \\
\hline Drinti-driving & \\
\hline I do not like to drive, but it is usually the fastest way to get where I need to go. & \\
\hline Chi-square statistic: 6.29 (p-value: 0.853 ) &
\end{tabular}

* Loadings from the factor analysis are suppressed by 0.30 .

For this analysis, 10 attitudinal questions were selected and the exploratory factor analysis with a maximum likelihood method and varimax rotation was performed. Factor analysis has been widely used for the data reduction and extracts the small sets of latent variables based on the correlated observed factors. Attitudinal questions in the survey were asked on a scale of 10, anchored by "strongly disagree" and "strongly agree." The Chi-square test from the factor analysis was used to determine the number of factors and four factors were extracted. The test shows that the null hypothesis, that is, "four factors are sufficient," cannot be rejected at the 0.05 level of significance, and they explain 45 percent of total variance ${ }^{5}$. All factors with relevant statements are presented in Table 1.

Loading represents the degree of correlation between a variable and a factor. The first factor was renamed as Pro-environment because all four questions that have high positive loadings are related to the environmental concerns and issues. The Flexibility factor includes responses to questions regarding complex trips with multiple-stops and the third factor, renamed as Pro-active transport, is positively associated with responses related to questions about public transit and walking. Finally, the fourth factor was renamed as Anti-driving, and it contains responses to the negative attitudinal questions regarding driving.

${ }^{4}$ Several transportation corridors where potential public transit improvements and toll alternatives are under investigation (or could be investigated in the future) were identified by the survey project team. Then 1400 participants who met the criteria (e.g., trip length, locations of origin, and destination) based on their travel diary were selected for the additional stated preference study.

${ }^{5}$ The explained variances of Pro-environment, Flexibility, Pro-active transport, and Anti-driving are 0.150, 0.126, 0.103, and 0.069 , respectively 


\section{$4 \quad$ Results}

Table 2 shows the basic statistics. After removing all missing values, the sample includes 749 adults. Average household size and number of workers are 2.35 and 1.30, respectively. Observations have approximately two vehicles on average and about 32 percent of them have pre-school or school-aged kids. Around 40 percent of observations are male, and the average age of respondents is 50.72 . Finally, the means of population and employment densities are 7.93 (residents/acre) and 3.92 (jobs/acre), respectively.

Simple linear and quadratic regressions with diverse socio-demographic characteristics, attitudinal factors as well as population and employment densities were used to examine the effects of densities on $\mathrm{CO}_{2}$ e emissions, and the results are shown in Table 3.

Table 2: Descriptive statistics

\begin{tabular}{lcccc}
\hline & Mean & SD & Min & Max \\
\hline Socio-demographics & & & & \\
\hline Household size & 2.347 & 1.205 & 1.000 & 7.000 \\
Number of workers & 1.304 & 0.845 & 0.000 & 4.000 \\
Number of vehicles & 1.953 & 0.971 & 0.000 & 6.000 \\
Total income ${ }^{6}$ & 8.175 & 3.921 & 1.000 & 16.000 \\
Kids (yes=1) & 0.316 & 0.465 & 0.000 & 1.000 \\
Gender (male=1) & 0.391 & 0.488 & 0.000 & 1.000 \\
Age & 50.718 & 13.875 & 16.000 & 85.000 \\
\hline Attitudinal factors (from factor analysis) & & & \\
\hline Pro-environment & 0.000 & 0.860 & -2.380 & 1.812 \\
Flexibility & 0.000 & 0.996 & -2.287 & 1.272 \\
Pro-active transport & 0.000 & 0.806 & -2.498 & 1.711 \\
Anti-driving & 0.000 & 0.703 & -1.904 & 1.693 \\
\hline Built environment & & & & \\
\hline Population density & & & & \\
(No. of residents/acre) & 7.928 & 7.310 & 0.053 & 68.902 \\
Employment density & & & & \\
(No. of jobs/acre) & 3.916 & 13.693 & 0.003 & \\
Sample size & 749 & & &
\end{tabular}

Most socio-demographic factors have significant influences on $\mathrm{CO}_{2}$ e emissions, and the results are consistent with previous studies. People from large families tend to produce fewer $\mathrm{CO}_{2} \mathrm{e}$ emissions possibly due to the reduced trips by coordinating activities or carpooling. As the accessibility to private vehicles increases, people tend to produce more $\mathrm{CO}_{2}$ e emissions. However, more care should be required to interpret this result because people who like driving may own more cars. In addition, rich people tend to generate more $\mathrm{CO}_{2}$ e emissions, possibly due to their economic ability to support private auto use. People who have pre-school or school-aged children produce more transportation emissions, possibly due to the increased escort trips for their children. There is also a significant difference between gender. Men tend to produce more $\mathrm{CO}_{2}$ e emissions compared to women. Moreover, older people are likely to drive more, producing more transportation emissions but the impact decreases as age increases.

Attitudinal factors are highly correlated with $\mathrm{CO}_{2}$ e emissions. People who have positive attitudes toward the environment, walking, or public transit tend to produce fewer transportation emissions. On the other hand, people who need flexibility for their daily activities tend to generate more transportation emissions. These results imply that travelers' attitudes are very influential determinants of $\mathrm{CO}_{2}$ e emissions, thus should be considered in the land use-transportation emissions analysis.

6 There are a total of 16 categories: less than $\$ 10,000 ; \$ 10,000-\$ 20,000 ; \$ 20,000-\$ 30,000$; etc. to $\$ 140,000-150,000$; and $\$ 150,000$ or more. The average mean value of 8.175 indicates that the total household income is between $\$ 70,000$ and $\$ 80,000$. 
Table 3: Simple linear and quadratic regressions for log transformed transportation emissions $\left(\mathrm{CO}_{2} \mathrm{e}\right)$

\begin{tabular}{|c|c|c|c|c|c|c|c|c|}
\hline & \multicolumn{4}{|c|}{ Linear regression } & \multicolumn{4}{|c|}{ Quadratic regression } \\
\hline & Estimate & SE & t-value & Sig. & Estimate & SE & t-value & Sig. \\
\hline Intercept & 1.0778 & 0.3296 & 3.2700 & 0.0011 & 1.2310 & 0.3333 & 3.6940 & 0.0002 \\
\hline \multicolumn{9}{|l|}{ Socio-demographics } \\
\hline Household size & -0.1300 & 0.0497 & -2.6160 & 0.0091 & -0.1293 & 0.0496 & -2.6080 & 0.0093 \\
\hline Number of workers & 0.0109 & 0.0491 & 0.2220 & 0.8247 & 0.0133 & 0.0489 & 0.2710 & 0.7864 \\
\hline Number of vehicles & 0.1236 & 0.0377 & 3.2740 & 0.0011 & 0.1099 & 0.0379 & 2.8970 & 0.0039 \\
\hline Household income & 0.0242 & 0.0084 & 2.8740 & 0.0042 & 0.0241 & 0.0084 & 2.8810 & 0.0041 \\
\hline Kids (yes=1) & 0.2480 & 0.1106 & 2.2420 & 0.0252 & 0.2457 & 0.1102 & 2.2300 & 0.0260 \\
\hline Gender $($ male $=1)$ & 0.1660 & 0.0603 & 2.7550 & 0.0060 & 0.1595 & 0.0601 & 2.6540 & 0.0081 \\
\hline Age & 0.0592 & 0.0128 & 4.6210 & 0.0000 & 0.0582 & 0.0128 & 4.5600 & 0.0000 \\
\hline $\mathrm{Age}^{2}$ & -0.0006 & 0.0001 & -4.5640 & 0.0000 & -0.0006 & 0.0001 & -4.5390 & 0.0000 \\
\hline \multicolumn{9}{|l|}{ Attitudinal factors } \\
\hline Pro-environment & -0.0798 & 0.0347 & -2.2980 & 0.0218 & -0.0756 & 0.0347 & -2.1790 & 0.0297 \\
\hline Flexibility & 0.1632 & 0.0296 & 5.5100 & 0.0000 & 0.1601 & 0.0295 & 5.4250 & 0.0000 \\
\hline Pro-active transport & -0.0761 & 0.0375 & -2.0290 & 0.0428 & -0.0624 & 0.0377 & -1.6560 & 0.0981 \\
\hline Anti-driving & -0.1007 & 0.0418 & -2.4080 & 0.0163 & -0.0938 & 0.0417 & -2.2460 & 0.0250 \\
\hline \multicolumn{9}{|l|}{ Built environment } \\
\hline Population density & -0.0152 & 0.0043 & -3.4990 & 0.0005 & -0.0283 & 0.0086 & -3.2780 & 0.0011 \\
\hline Population density ${ }^{2}$ & & & & & 0.0003 & 0.0002 & 2.1220 & 0.0342 \\
\hline Employment density & -0.0060 & 0.0023 & -2.6350 & 0.0086 & -0.0152 & 0.0056 & -2.6970 & 0.0072 \\
\hline Employment density ${ }^{2}$ & & & & & 0.0000 & 0.0000 & 1.8390 & 0.0663 \\
\hline $\mathrm{N}$ & 749 & & & & 749 & & & \\
\hline $\mathrm{R}$-square & 0.1915 & & & & 0.2004 & & & \\
\hline Adjusted R-square & 0.1760 & & & & 0.1829 & & & \\
\hline
\end{tabular}

Two density variables show very significant negative impacts on $\mathrm{CO}_{2}$ e emissions. Residents in denser areas tend to produce fewer transportation emissions possibly due to the increased accessibility to public transit and other land uses. In addition, people living in neighborhoods where more jobs are located tend to drive less, resulting in fewer $\mathrm{CO}_{2}$ e emissions. These results support that land-use planning can be a good policy instrument for reducing transportation emissions through modifying travel behavior. However, the result from a quadratic regression provides the evidence of the non-linear relationship between the population density and $\mathrm{CO}_{2} \mathrm{e}$ emissions. That is, the negative influence of population density decreases as density increases. Therefore, it is also possible that after reaching a certain threshold, the effect of population density becomes insignificant or can be reversed.

For the further analysis, five sub-group variables created based on the number of travelers and population density are employed, and results are shown in Table 4. In addition, the distance from the CBD is added in the model to reduce possible confounding effects of other built environment factors. This variable is often used to represent the level of accessibility since many jobs and other diverse activities are located in the CBD, and several studies showed that it is one of the most influential factors among other built environment measures in explaining travel behavior (Ewing and Cervero 2010; Hong, Shen, and Zhang 2014; Zegras 2010).

All socio-demographic characteristics and attitudinal factors show the consistent results with the previous analysis. To analyze the non-linear relationship between the population density and $\mathrm{CO}_{2} \mathrm{e}$ emissions, Den_group 5 (i.e., 20 percent of total travelers who live in the most densely populated census tracts) is set up as a baseline category and compared to other groups. 
Table 4: Linear regressions for log transformed transportation emissions $\left(\mathrm{CO}_{2} \mathrm{e}\right)$ with population density group indicators (sub-groups) and accessibility

\begin{tabular}{|c|c|c|c|c|c|c|c|c|}
\hline & \multicolumn{4}{|c|}{ Regression (sub-groups) } & \multicolumn{4}{|c|}{ Regression (sub-groups and accessibility) } \\
\hline & Estimate & SE & t-value & Sig. & Estimate & SE & t-value & Sig. \\
\hline Intercept & 0.7227 & 0.3298 & 2.1910 & 0.0287 & 0.5854 & 0.3273 & 1.7880 & 0.0741 \\
\hline \multicolumn{9}{|l|}{ Socio-demographics } \\
\hline Household size & -0.1221 & 0.0520 & -2.4340 & 0.0152 & -0.1281 & 0.0496 & -2.5830 & 0.0100 \\
\hline Number of workers & 0.0167 & 0.0493 & 0.3400 & 0.7342 & 0.0157 & 0.0487 & 0.3230 & 0.7470 \\
\hline Number of vehicles & 0.1251 & 0.0380 & 3.2940 & 0.0010 & 0.1022 & 0.0379 & 2.6970 & 0.0072 \\
\hline Household income & 0.0237 & 0.0085 & 2.7840 & 0.0055 & 0.0305 & 0.0086 & 3.5660 & 0.0004 \\
\hline Kids (yes=1) & 0.2574 & 0.1113 & 2.3120 & 0.0210 & 0.2760 & 0.1101 & 2.5080 & 0.0124 \\
\hline Gender $($ male $=1)$ & 0.1543 & 0.0605 & 2.5490 & 0.0110 & 0.1504 & 0.0598 & 2.5140 & 0.0122 \\
\hline Age & 0.0578 & 0.0129 & 4.4640 & 0.0000 & 0.0584 & 0.0128 & 4.5680 & 0.0000 \\
\hline $\mathrm{Age}^{2}$ & -0.0006 & 0.0001 & -4.3730 & 0.0000 & -0.0006 & 0.0001 & -4.4420 & 0.0000 \\
\hline \multicolumn{9}{|l|}{ Attitudinal factors } \\
\hline Pro-environment & -0.0783 & 0.0351 & -2.2300 & 0.0261 & -0.0595 & 0.0350 & -1.7020 & 0.0892 \\
\hline Flexibility & 0.1614 & 0.0298 & 5.4120 & 0.0000 & 0.1481 & 0.0296 & 5.0000 & 0.0000 \\
\hline Pro-active transport & -0.0727 & 0.0379 & -1.9210 & 0.0552 & -0.0420 & 0.0381 & -1.1050 & 0.2695 \\
\hline Anti-driving & -0.0981 & 0.0421 & -2.3310 & 0.0200 & -0.1073 & 0.0416 & -2.5770 & 0.0102 \\
\hline \multicolumn{9}{|c|}{ Population Density groups } \\
\hline Den_group 1 & 0.3618 & 0.0958 & 3.7750 & 0.0002 & 0.1795 & 0.1035 & 1.7340 & 0.0833 \\
\hline Den_group 2 & 0.3360 & 0.0936 & 3.5880 & 0.0004 & 0.2224 & 0.0961 & 2.3140 & 0.0209 \\
\hline Den_group 3 & 0.2273 & 0.0945 & 2.4040 & 0.0165 & 0.0965 & 0.0981 & 0.9840 & 0.3254 \\
\hline Den_group 4 & 0.1149 & 0.0931 & 1.2330 & 0.2179 & 0.0399 & 0.0936 & 0.4260 & 0.6701 \\
\hline \multicolumn{9}{|l|}{ Accessibility } \\
\hline \multicolumn{9}{|l|}{ Distance from CBD } \\
\hline (miles) & & & & & 0.0177 & 0.0041 & 4.3560 & 0.0000 \\
\hline $\mathrm{N}$ & 749 & & & & 749 & & & \\
\hline R-square & 0.1837 & & & & 0.2043 & & & \\
\hline Adjusted R-square & 0.1658 & & & & 0.1858 & & & \\
\hline
\end{tabular}

The result indicates that people living in less dense neighborhoods tend to produce more $\mathrm{CO}_{2} \mathrm{e}$ emissions, but there is no significant difference in $\mathrm{CO}_{2}$ e emissions between people in the Den_group 4 and Den_group 5. The model with the Distance from CBD variable (the second model in Table 4) shows that people living farther from the $\mathrm{CBD}$ are likely to produce more $\mathrm{CO}_{2}$ e emissions. In addition, the influences of density become weak. Specifically, only people in Den_group 1 and Den_group 2 compared to people in Den_group 5 produce more $\mathrm{CO}_{2} \mathrm{e}$ emissions and these associations are statistically significant at the 0.10 and 0.05 levels, respectively. In sum, these empirical results suggest that the effect of population density on transportation emissions is no longer significant after reaching a certain level of densification.

\section{Conclusions}

Land-use policy has been proposed as a fundamental way to encourage people to become more ecofriendly travelers even though it is a long-term strategy compared to other technological approaches such as electrification or alternative fuels. Many empirical studies have found its effectiveness; however, most of their results are limited due to the linear assumption between land-use factors and transportation emissions. This study employs a quadratic form of population and employment densities and sub-group 
indicators created based on population density to assess their non-linear relationships with $\mathrm{CO}_{2} \mathrm{e}$ emissions. It should be also noted that the relationship between $\mathrm{CO}_{2}$ e emissions and energy use is set for a fixed vehicle fleet; therefore, the results found in this study could easily be applied to the relationship between the built environment and total energy use. Four policy implications are generated from this study.

First, this study finds that densities have strong negative associations with transportation emissions. That is, residents living in denser neighborhoods produce fewer transportation emissions. In addition, people living in neighborhoods where many jobs are located tend to generate fewer transportation emissions, mainly due to the short commuting trips. These results are consistent with previous land usetransportation emissions analyses (Hong and Goodchild 2014; Stone, 2007) and support the claim of smart growth, implying the usefulness of land-use policy.

Second, even though densities are significantly negatively associated with transportation emissions, their relationships are non-linear. For example, the negative association between population density and $\mathrm{CO}_{2}$ e emissions becomes weak as population density increases, and possibly become insignificant after reaching a certain level of population density. Transportation emissions are sensitive to VMT, travel speed, and vehicle characteristics, and density is associated with them. The additional analysis shows that, even though people living in low-density areas tend to drive more light-duty trucks instead of passenger cars than people living in high-density areas, they tend to have higher speeds and drive newer cars than residents in high-density areas ${ }^{7}$.

Third, the result shows that increasing accessibility can be a good policy strategy to reduce transportation emissions. This also implies that infill redevelopment can be more beneficial to our environment than suburban developments.

Lastly, people's attitudes toward transportation modes and environment are influential determinants in explaining transportation emissions. People who care about the environment or dislike driving tend to generate fewer transportation emissions. Therefore, planners and policy makers should pay more attention on how to change people's attitudes as well as land-use policies.

There are several limitations in this study. First, examining possible non-linear relationships of diverse built environment characteristics such as mixed use, pedestrian infrastructure and transit systems can provide more useful information to planners. Second, it is still not enough to provide causality. Adding attitudinal factors can relieve the spurious effects caused by self-selection; however, it does not consider the time precedence issue (i.e., the cause precedes the effect). Thus, utilizing a panel study with attitudinal factors will be necessary for future research. Lastly, more case studies are required to generalize findings.

${ }^{7}$ The median road speeds for group 1 and group 5 are 35.37 and $33.45 \mathrm{mph}$, respectively, and the average vehicle ages are 6.64 and 7.95 years for group 1 and group 5, respectively. 


\section{References}

Barla, P., L. F. Miranda-Moreno, N. Savard-Duquet, M. Theriault, and M. Lee-Gosselin. 2010. Disaggregated empirical analysis of determinants of urban travel greenhouse gas emissions. Transportation Research Record 2156: 160-169.

Boarnet, M. G., and R. Crane. 2001. The influence of land use on travel behavior: Specification and estimation strategies. Transportation Research Part A 35: 823-845.

Brownstone, D., and T. F. Golob. 2009. The impact of residential density on vehicle usage and energy consumption. Journal of Urban Economics 65: 91-98.

Cao, X., S. Handy, and P. Mokhtarian. 2006. The influences of the built environment and residential self-selection on pedestrian behavior: Evidence from Austin, TX. Transportation 33: 1-20.

Cao, X., P. Mokhtarian, and S. Handy. 2009. The relationship between the built environment and nonwork travel: A case study of Northern California. Transportation Research Part A 43: 548-559.

Cao, X., X. Xu, and Y Fan. 2010. Exploring the connections among residential location, selfselection, and driving: Propensity score matching with multiple treatments. Transportation Research Part A 44: 797-805.

Cervero, R. 1996. Mixed land-uses and commuting: Evidence from the American Housing Survey. Transportation Research Part A 30: 361-377.

Cervero, R., and M. Duncan. 2002. Residential SelfSelection and Rail Commuting: A Nested Logit Analysis. California: University of California Transportation Center Berkeley.

Chen, C., H. Gong, and R. Paaswell. 2008. Role of the built environment on mode choice decisions: Additional evidence on the impact of density. Transportation 35: 285-299.

Crange, R. 2000. The influence of urban form on travel: An interpretive review. Journal of Planning Literature 15: 3-23.

EPA 2006. Greenhouse Gas Emissions from the U.S. Transportation Sector, 1990-2003. Washington, DC: Environmental Protection Agency.

Ewing, R., and R. Cervero. 2010. Travel and the built environment. Journal of the American Planning Association 76: 265-294.

Fang, H. A. 2008. A discrete-continuous model of households' vehicle choice and usage, with an application to the effects of residential density. Transportation Research Part B 42: 736- 758.

Frank, L. D., M. Bradley, S. Kavage, J. Chapman, and T. K. Lawton. 2008. Urban form, travel time, and cost relationships with tour complexity and mode choice. Transportation 35: 37-54.

Frank, L. D., and P. Engelke. 2005. Multiple impacts of the built environment on public health: Walkable places and the exposure to air pollution. International Regional Science Review 28: 193-216.

Frank, L. D., M. J. Greenwald, S. Kavage, and A. Devlin. 2011. An assessment of urban form and pedestrian and transit improvements as an integrated GHG reduction strategy. Madison, WI: Wisconsin Department of Transportation.

Frank, L. D., B. Saelens, K. E. Powell, and J. E. Chapman. 2007. Stepping towards causation: Do built environments or neighborhood and travel preferences explain physical activity, driving, and obesity? Social Science \& Medicine 65: 1898-1914.

Frank, L. D., J. F. Sallis, T. L. Conway, J. E. Chapman, B. E. Saelens, and W. Bachman 2006. Many pathways from land use to health: Associations between neighborhood walkability and active transportation, body mass index, and air quality. Journal of the American Planning Association 72: 75-87.

Frank, L. D., B. Stone, and W. Bachman. 2000. Linking land use with household vehicle emissions in the central Puget Sound: Methodological framework and findings. Transportation Research Part D 5: 173-196. 
Friedman, M. S., K. E. Powell, L. Hutwagner, L. M. Graham, and W. G. Teaque. 2001. Impact of changes in transportation and commuting behaviors during the 1996 Summer Olympic Games in Atlanta on air quality and childhood asthma. The Journal of American Medical Association 285: 897-905.

Handy, S. 2005. Smart growth and the transportation-land use connection: What does the research tell us? International Regional Science Review 28: 146-167.

Handy, S. 2006. Self-selection in the relationship between the built environment and walking. Journal of the American Planning Association 72: 55-74.

Handy, S., X. Cao, and P. L. Mokhtarian. 2005. Correlation or causality between the built environment and travel behavior? Evidence from Northern California. Transportation Research Part D 10: 427-444.

Hong, J., and A. Goodchild. 2014. Land use policies and transport emissions: Modeling the impact of trip speed, vehicle characteristics and residential location. Transportation Research Part D 26: 47-51.

Hong, J., and Q. Shen. 2014. Residential density and transportation emissions: Examining the connection by addressing spatial autocorrelation and self-selection. Transportation Research Part D 22: 7579.

Hong, J., Q. Shen, and L. Zhang. 2014. How do built-environment factors affect travel behavior? A spatial analysis at different geographic scales. Transportation 41: 419-440.

Krizek, K. J. 2003a. Neighborhood services, trip purpose, and tour-based travel. Transportation 30: 387-410.

Krizek, K. J. 2003b. Residential relocation and changes in urban travel: Does neighborhood-scale urban form matter. Journal of the American Planning Association 69: 265-281.

Lee, S., and B. Lee. 2014. The influence of urban form on GHG emissions in the U.S. household sector. Energy Policy 68: 534-549.

Mokhtarian, P. L., and X. Cao. 2008. Examining the impacts of residential self-selection on travel behavior: A focus on methodologies. Transportation Research Part B 42: 204-228.

Schwanen T., and P. Mokhtarian. 2005. What affects commute mode choice: Neighborhood physical structure or preferences toward neighborhoods? Journal of Transport Geography 13: 83-99.

Stone, B. 2007. Urban sprawl and air quality in large US cities. Journal of Environmental Management 86: 688-698.

Zegras, C. 2010. The built environment and motor vehicle ownership and use: Evidence from Santiago de Chile. Urban Studies 47: 1793-1817.

Zhang L., J. Hong, A. Nasri, and Q. Shen. 2012. How built environment affects travel behavior: A comparative analysis of the connections between land use and vehicle miles traveled in US cities. Journal of Transport and Land Use 5: 40-52. 